\title{
O ZONAL E O AZONAL NA INTERPRETAÇÃO E NA CLASSIFICAÇÃO DOS GEOSSISTEMAS DO MUNICÍPIO DE LIMA DUARTE, ZONA DA MATA MINEIRA
}

\author{
Roberto Marques Neto* \\ Universidade Federal de Juiz de Fora
}

\begin{abstract}
Resumo: O domínio tropical atlântico do sudeste brasileiro apresenta compartimentos geomorfológicos montanhosos que se consubstanciam, sobretudo, em zonas de cisalhamento reativadas de forte expressão no relevo, o que engendra elementos azonais na estruturação dos geossistemas regionais. O município de Lima Duarte, localizado na Zona da Mata Mineira, apresenta distintamente uma interpenetração de componentes zonais e azonais na composição das paisagens que ocorrem no território municipal, sendo que o estudo destas paisagens pela óptica geossistêmica é que encerra os objetivos do presente artigo, cuja fundamentação teórica e metodológica se assenta nos pressupostos desenvolvidos na corrente moderna do pensamento geográfico russo-soviético.
\end{abstract}

Palavras-chave: Geossistema. Lima Duarte. Cristas quartzíticas. Campos rupestres.

THE ZONAL AND THE AZONAL IN THE INTERPRETATION AND IN THE CLASSIFICATION OF GEOSYSTEMS IN THE CITY OF LIMA DUARTE, ZONA DA MATA OF MINAS GERAIS

Abstract: The Atlantic tropical domain on the Brazilian southeast presents geomorphological mountainous compartments that are consolidated mainly in reactivated shear zones with strong expression in the relief what engenders azonal elements in the regional geosystems structuration. The city of Lima Duarte located in Zona da Mata of Minas Gerais distinctively presents an interpenetration of zonal and azonal components in the composition of the landscapes occurring in the municipal territory wherein the studies of those landscapes in the geosystemic optics is what the objectives of the present article comprehends which theoretical and methodological substantiation is settled in the presuppositions developed in the Russian-Soviet scope.

Keywords: Geosystem. Lima Duarte. Quartzitic combs. Rocks fields.

\section{EL ZONAL Y EL AZONAL EN LA INTERPRETACIÓN Y EN LA CLASIFICACIÓN DE LOS GEOSISTEMAS DEL MUNICIPIO DE LIMA DUARTE, ZONA DE LA MATA MINERA}

Resumen: El dominio tropical atlántico del sudeste brasileño presenta compartimentos geomorfológicos montañosos que se consubstancian sobre todo en zonas de cizallamiento reactivadas de fuerte expresión en el relieve, lo que engendra elementos azonales en la estructuración de los geosistemas regionales. El municipio de Lima Duarte, ubicado en la Zona de la Mata Minera, presenta claramente una interpenetración de componentes zonales y azonales en la composición de los paisajes que ocurren en el territorio municipal, siendo que el estudio de estos paisajes por la óptica geosistémica es que encierra los objetivos del presente artículo, cuya fundamentación teórica y metodológica se asienta en los presupuestos desarrollados en la corriente moderna del pensamiento geográfico ruso-soviético.

Palabras- clave: Geosistema. Lima Duarte. Sierras quartzíticas Campos rupestres. 
Introdução

Os mapeamentos taxocorológicos de geossistemas se disseminaram a partir das proposições de Viktor B. Sochava na década de sessenta do século passado, que estruturou uma conduta interpretativa e classificatória a partir de unidades materializadas em diferentes níveis hierárquicos, cada nível formado pelo princípio do agrupamento de níveis hierárquicos inferiores, concatenando o sistema Terra (envoltura geográfica) (Riabchicov, 1976) com as unidades espaciais de manifestação local (fácies físico-geográficas) através de uma série de grandezas intermediárias, cada uma delas dotada de uma expressão concreta no espaço geográfico. Tal proposta de classificação considera que os geossistemas são formados por integridades homogêneas (geômeros) e heterogêneas (geócoros), coadunadas em um princípio bilateral pelo qual um grupo de geômeros elementares (áreas homogêneas elementares) interpenetrados faz por consubstanciar um geócoro elementar, composição heterogênea que se projeta em fácies, nível hierárquico imediatamente superior na fileira oposta. A elucidação de tais pressupostos foi trazida a lume pelo geógrafo eslavo em uma série de publicações (SOCHAVA, 1971; 1977; 1978; 1978a).

$\mathrm{Na}$ antiga União Soviética e países de sua esfera geopolítica e ideológica, bem como na atual Federação Russa, o estudo dos geossistemas a partir de suas formulações iniciais atravessou os anos de Guerra Fria e se faz perdurar com notável fôlego e auspicioso avanço, atendendo em alta demanda as necessidades por diagnósticos físico-territoriais, inventários, zoneamentos e demais estudos do patrimônio natural dos vastos espaços daquele país. Por conseguinte, um volume imenso de trabalhos foi sendo divulgado ao longo das últimas décadas (SAUSHKIN; SMIRNOV, 1968; YEFREMOV, 1969; PLAKHOTNIK, 1973; ISACHENKO, 1973; DEMEK, 1978; PREOBRAZHENSKIY, 1983; HAASE, 1989; KHOROSHEV; ALESHENKO, 2008; GANZEI, 2008; STYNKO; SEMENOV, 2008; ABALAKOV; SEDYKH, 2010; KUZMENKO, 2011; KUZNETSOVA ET AL. 2011; LYSANOVA ET AL., 2011; LAVRINENKO, 2012; SUVOROV; KITOV, 2013; MAKUNINA, 2014); ficam registrados os trabalhos retrocitados a título de amostragem entre a plêiade de pesquisas geossistêmicas divulgadas no âmbito eslavo. No Brasil, ainda são poucos os trabalhos explicitamente firmados nos pressupostos russo-soviéticos (MARQUES NETO, 2012; CAVALCANTI, 2013; OLIVEIRA, 2013).

As interferências complementares e recíprocas dos elementos zonais e azonais na composição da paisagem foram encarnadas nas proposições de Isachenko (1973) e fundamentaram uma série de propostas de regionalização natural. Basta se voltar para a proposição de Walter (1984) e seus zonobiomas, definidos a partir dos fatores hidrotérmicos zonalmente controlados, depositários de unidades azonais influenciadas por fatores edáficos, geomorfológicos e litológicos (pedobiomas, orobiomas, litobiomas). Nesse rol também se inscrevem os domínios de natureza do Brasil (AB'SÁBER, 2003), definidos por fatores climáticos, morfopedológicos e bióticos e materializados em famílias de ecossistemas. Por esse prisma, Cavalcanti (2013) elaborou um esquema regional no estudo e na classificação dos geossistemas do Parque Nacional do Catimbau (PE), contribuindo tanto no plano metodológico como no conhecimento acerca da estrutura e dinâmica da paisagem no semiárido brasileiro.

Sensível à influência mútua entre os fatores zonais e azonais na composição e no funcionamento da paisagem, o presente trabalho se encerra na interpretação, classificação e mapeamento dos geossistemas para o município de Lima Duarte (MG), estruturando seu corte metodológico no princípio bilateral de classificação propugnado por V. B. Sochava associado às proposições de Isachenko (1973). A diversificação geomorfológica e alguns contrastes litoestruturais conferem para este segmento da Zona da Mata Mineira uma intensificação das relações entre as formas e os processos diretamente ligados à zonalidade climática e aos padrões genéticos e dinâmicos de ordem azonal.

\section{Procedimentos metodológicos}

0 estudo dos processos vigentes conformando os fluxos de massa e energia que perpassam as estruturas dos geossistemas demanda um enfoque dinâmico na investigação das formas e dos processos naturais operantes nas paisagens em conexão com a esfera socioeconômica. No intuito de abranger o enfoque em questão, adotou-se a escala de $1 / 50.000$ para o estudo das integridades espaciais homogêneas e heterogêneas que compõem as unidades geossistêmicas da área de estudo, interpretadas em seus níveis topológicos correspondentes aos grupos de fácies/mesogeócoros.

A pesquisa partiu de um inventário do meio físico em seus aspectos fundamentais e em suas relações com o atual quadro de humanização por meio das unidades de uso da terra existentes. 0 relevo foi estudado em suas formas, em seus processos superficiais vigentes e em suas relações com a cobertura pedológica, tendo sido elaborada uma carta geomorfológica a partir de uma abordagem integrada entre a proposta de Ross (1992) 
e o sistema metodológico de Nunes et al. (1994), sendo o produto cartográfico digitalizado em software ArcGIS (MARQUES NETO et al., 2015). Como subsídio foi gerada uma carta de solos que partiu da interpretação das unidades de mapeamento discernidas em projeto oficial levado a efeito pela Universidade Federal de Viçosa e Universidade Federal de Lavras (2010), realizandose caracterizações macromorfológicas em campo em adesão parcial aos procedimentos enumerados por Lemos e Santos (1978) para fins de interpretação da dinâmica superficial e para a dissociação de unidades de mapeamento interpretadas a partir dos dados de campo e dos procedimentos de interpretação das folhas topográficas e imagens de satélite. Tal conjunto de procedimentos foi complementado com a coleta de amostras e subsequente submissão para análise textural e química (fertilidade + matéria orgânica) no Laboratório de Solos da Universidade Federal de Lavras.

A classificação da cobertura vegetal utilizou-se das imagens de satélite TM-Landsat (composição de bandas 5, 4, 3 e 3, 2, 1) e do software ENVI 5.0, ambiente no qual se lançou mão da ferramenta classificação supervisionada, utilizando-se a amostragem dos pixels referentes a cada classe de uso da terra e cobertura vegetal. A nomenclatura das fisionomias florestais se deu em conformidade com a proposta classificatória do Instituto Brasileiro de Geografia e Estatística (1992).

A rede de drenagem foi interpretada a partir da concepção metodológica inerente aos estilos fluviais (river styles), desenvolvida por Brierley e Fryrs (2005), e que classifica diferentes segmentos de um canal fluvial de acordo com seus aspectos geomorfológicos e hidrodinâmicos. No presente trabalho, a concepção metodológica em questão foi pensada de forma mais genérica no que tange aos seus "parâmetros chave", procurando-se relacionar as características gerais dos diferentes estilos de canais ao longo das unidades geossistêmicas nos termos das conexões entre a rede hidrográfica e as demais estruturas da paisagem. Nesse sentido, foram consideradas as relações com compartimentos geomorfológicos, com as características do vale e do canal, e com unidades geomorfológicas dominantes, abdicando-se de um enfoque mais específico pautado na interpretação morfoestratigráfica dos materiais transportados e depositados e na elaboração de secções transversais de detalhe, em função do próprio caráter acessório e subsidiário da abordagem em questão no âmbito do trabalho que aqui se divulga. A área de estudo foi então zoneada segundo o predomínio de vales encaixados (ou confinados), parcialmente confinados e abertos (não confinados), a exemplo do que fora levado a efeito por
Lima e Marçal (2013). Os tipos de canais dominantes foram diferenciados em retilíneos, sinuosos, meandrantes encaixados e meandrantes divagantes, empregando-se recurso gráfico de simbologia para representação na legenda dos geossistemas.

Os documentos cartográficos referentes ao relevo (declividade e carta geomorfológica), solos, uso da terra e cobertura vegetal foram sobrepostos para geração de uma carta de fragilidade ambiental, informadora categórica de aspectos importantes da dinâmica da paisagem e de interesse direto aos programas de uso da terra a partilharem do planejamento físico-territorial municipal, fechando-se assim o conjunto de informações básicas para a interpretação geossistêmica. Tais documentos cartográficos de base não foram aqui apresentados em função do espaço demasiado que ocupam, porém podem ser consultados em remissão a Marques Neto et al. (2014).

Doravante, foi levada a efeito a correlação entre as informações básicas geradas para abstração de integridades espaciais concretas em Lima Duarte que se diferenciam segundo sua estrutura e sua dinâmica, materializadas em mosaicos heterogêneos formados por objetos (geócoros) que integrados assumem um princípio de unidade, formando uma categoria homogênea (geômero) com funcionamento próprio. Por meio do princípio bilateral de organização da informação proposto por Sochava $(1971 ; 1978 ; 1978 a)$, portanto, é que se procedeu na interpretação e na classificação dos geossistemas. A este raciocínio foi integrado o pensamento de Isachenko (1973), distinguindo-se as unidades com predomínio de elementos zonais e as unidades com predomínio de elementos azonais, ainda que não se tenha estabelecido unidades derivadas em função da alçada sub-regional da presente investigação. Por critério, os traços da tropicalidade (elementos zonais) foram interpretados a partir dos modelados convexos com mantos de alteração argilosos espessos e coberturas pedológicas de organização estrutural latossólica e argilúvica sob florestas, vigentes ou originalmente, bem como em apreço ao clima e ao gradiente altitudinal vigente na área de estudo; os elementos azonais, por seu turno, foram considerados a partir dos modelados de dissecação elevados (cristas e demais patamares de cimeira interfluviais) submetidos a controle estrutural, com solos rasos, imaturos e pouco intemperizados (Neossolos e Cambissolos) sob fisionomias vegetais de campos influenciadas por fatores edáficos. Destas correlações derivam os grandes arranjos paisagísticos regionais.

A proposta de mapeamento se integra aos chamados mapas regionais-tipológicos (ABALAKOV; 
SEDYKH, 2010), que representam tanto os geócoros (indivíduos geográficos) como os geômeros (tipos de paisagem). A expressão espacial sub-regional de Lima Duarte demandou o emprego da escala de 1/50.000, compatível com uma resolução capaz de representar grupos de fácies/mesogeócoros como unidades elementares de mapeamento, agrupadas em classes de fácies pertencentes aos geossistemas regionais (macrogeócoros) (sensu SOCHAVA, 1978) abrangidos pelos limites da área de estudo. Em analogia a outros sistemas de classificação, os macrogeócoros correspondem aos geossistemas da classificação original de Bertrand (1971), conforme promulgado pelo próprio Sochava (1978), não havendo correspondência direta entre os grupos de fácies e os níveis inferiores promulgados pelo geógrafo de Tolouse (geofácies e geotopos). 0 macrogeócoro poderia ser tomado como análogo à paisagem (landschaft) ou ao chamado "okrug" natural, ou mesmo ao conceito de raion definido por Isachenko (SOCHAVA, 1978). Em certa medida, encontra alguma correspondência com o conceito de unidades de terras (land unit) concernente ao método australiano desenvolvido no âmbito da CSIRO (Comunidade Científica e Organização da Pesquisa Industrial) no formato pelo qual foi incorporado pelos geógrafos holandeses (ZONNEVELD, 1989), onde a concepção da land unit é tomada como sinônimo de paisagem (ROSS, 2009).

Foi lançado mão do emprego de cores distintas na representação dos limites macro e mesogeocóricos, permitindo uma resolução cartográfica proficiente da projeção dos geossistemas regionais na área de estudo e, ao mesmo tempo, da forma em que se organizam em integridades topológicas. Ainda, os geossistemas foram representados segundo o grau de humanização em adaptação à concepção metodológica de Rodriguez et al. (2010), discernindo-se geossistemas com predomínio de estruturas naturais (extensões com vegetação nativa e antropização rarefeita a ausente), predomínio de estruturas antroponaturais (mosaicos rurais que intercalam fragmentos de vegetação nativa com unidades de uso econômico) e predomínio de estruturas antropogênicas (áreas urbanas, industriais, de mineração e afins).

A área de estudo e sua contextualização no quadro regional

Posicionado no extremo sul da Zona da Mata Mineira, o município de Lima Duarte esbanja uma considerável área territorial de $848,48 \mathrm{~km} 2$ distribuída nas Bacias do Alto Rio Grande (pertencente à grande Bacia Hidrográfica do rio Paraná) e do Rio do Peixe, pertencente à Bacia do Rio Paraíba do Sul (Figura 1). A evolução e a dinâmica do relevo, portanto, são controladas por diferentes níveis de base, um deles numa faixa de 1.000 metros de altitude referente à calha do rio Grande, e outro aquém de 800 metros correspondente à passagem do rio do Peixe, que se articula ao oceano Atlântico tendo no rio Paraíba do Sul um nível de base intermediário pouco à jusante de sua confluência com o rio Preto. Sobre esta superfície agradacional, correspondente a um segmento da planície fluvial do rio do Peixe, se ergue a maior parte da sede municipal, definindo-se um aspecto longilíneo para o diminuto sítio urbano, que circunstancialmente se espraia em direção aos modelados denudacionais que estabelecem rupturas de declive com o plano alúviocoluvionar.

Litotipos gnáissicos enfeixam-se a conformarem um setor intermontano emoldurado em morros e morrotes de considerável declive, ainda assim recobertos por coberturas argilosiltosas em franca pedogênese latossólica em parte caracterizada por latolização em materiais coluviais retrabalhados. Esta morfologia mamelonizada e de convexação bem marcada é interrompida pela passagem de cristas quartzíticas que se sobressaem acima de 1.500 metros de altitude, constituindo relevo de aspecto escarpado talhado em falhas normais com desalinhamentos ocasionados por deslocamentos devidos a falhas transcorrentes. Os afloramentos são extensivos e as coberturas eminentemente arenosas, ocorrendo na forma de solos rasos e imaturos (Neossolo Litoólico e Regolítico), com alguma ocorrência de Cambissolos.

A relação rocha/relevo/coberturas superficiais que se definem nos domínios gnáissico-graníticos e quartzíticos se projeta na cobertura vegetal nativa. Os campos rupestres medram nos ambientes altimontanos sobre o substrato quartzítico, e em setores preservados como aquele existente no Parque Estadual do Ibitipoca se desdobram em variadas sinúsias, de campos herbáceos relativamente homogêneos e de dominância ecológica bem marcada até arbustais e nanoflorestas de maior diversidade e mais bem servidos em massa lenhosa. Os remanescentes florestais são mantidos em alguns segmentos das encostas serranas em fisionomias de Floresta Ombrófila Densa. Sobre os morros mais rebaixados formata-se um mosaico caracterizado por uma situação mais fragmentária da mata dada pela presença de fragmentos de Floresta Estacional Semidecidual intercalada a áreas de pastagem, fundamentalmente. A parte oeste do município, pertencente à Bacia do Rio Grande, tem grandes especificidades. Transposta a faixa interfluvial 
eclode um relevo colinoso revestido por campos limpos e sujos nativos sobre solos profundos que suspeitamos se tratar de relíquias paleoclimáticas cuja manutenção teria sido favorecida pela posição elevada da calha do rio Grande e fatores térmicos associados que facilitam a ocorrência de campos abaixo das altitudes normais nas quais estas fisionomias ocorrem no Brasil Sudeste.
Desafortunadamente, estas paisagens sui generis vêm sendo agredidas pelo avanço despudorado do Eucalyptus, cuja influência na região de ocorrência dos campos encontra-se atualmente consolidada.

Em geral, os campos altimontanos coincidem com o clima tropical de altitude caracterizado pela existência de uma célula de maior pluviosidade ao longo da Serra

Figura 1 - Localização do município de Lima Duarte.

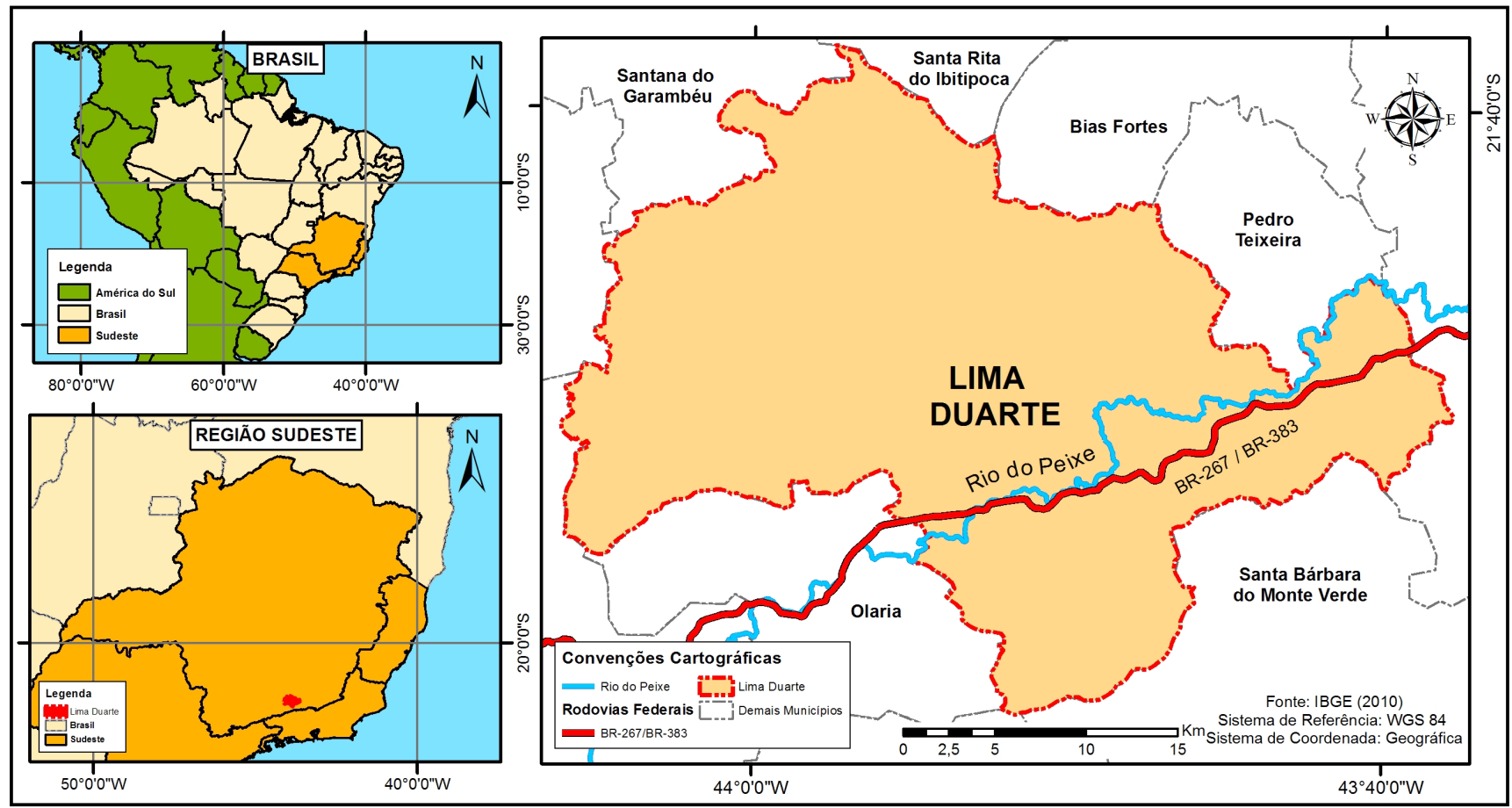

Fonte: Marques Neto et al. (2014)

do Ibitipoca, onde os volumes podem atingir $2000 \mathrm{~mm}$ anuais. 0 clima tropical típico se configura nas áreas mais baixas que chegam a estabelecer desníveis próximos a 900 metros em relação aos pontos culminantes, definindo-se notável diversidade climática em um território municipal cujas amplitudes altimétricas são superadas apenas nas regiões da Serra do Brigadeiro e do maciço do Caparaó no concernente ao espaço que compreende a Zona da Mata Mineira.

Geossistemas em Lima Duarte: dimensões zonais e azonais na estrutura e na dinâmica da paisagem

O relevo tem forte controle na distribuição dos geossistemas em Lima Duarte e, por vezes, se oferece como importante critério de delimitação das unidades de mapeamento. A presença de cristas elevadiças diversifica a coleção de geoformas existentes na área estudada e engendra a emergência de fortes componentes azonais a partilharem da composição dos geossistemas regionais. As unidades de mapeamento (Figura 2) correspondem aos grupos de fácies, integridades espaciais condizentes com uma interpretação proficiente da paisagem em perspectiva genético-estrutural e adequada à grandeza territorial do município. Em função do grande número de informações acerca de elementos genético-estruturais e dinâmicos da paisagem que partilham da presente interpretação, a legenda para o mapa de unidades geossistêmicas segue apresentada em figura à parte (Figura 3). 
Figura 2 - Espacialização das unidades geossistêmicas de Lima Duarte (MG).

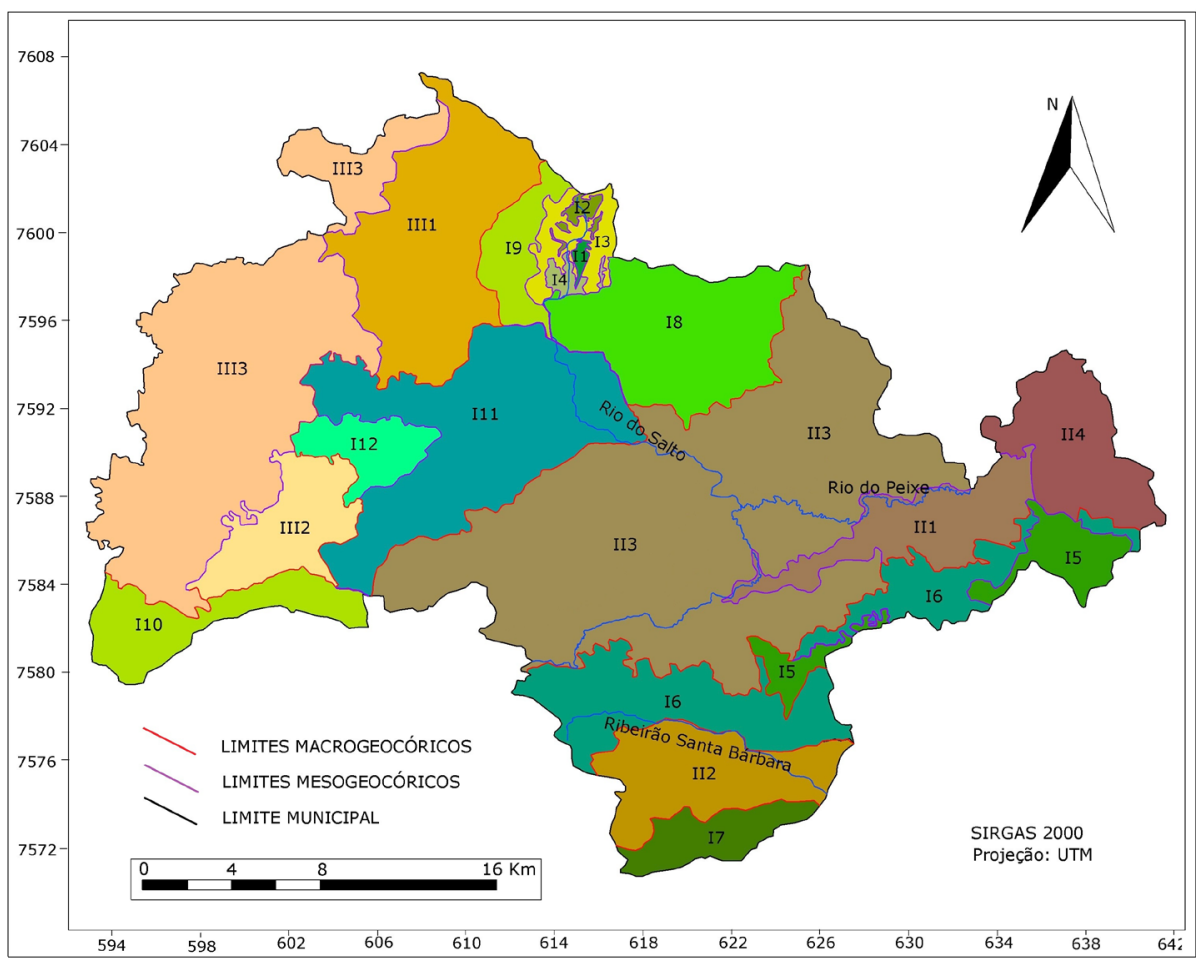

Elaborado pelo autor

Figura 3 - Legenda do mapa de unidades geossistêmicas e seus principais aspectos genéticos-estruturais e dinâmicos.

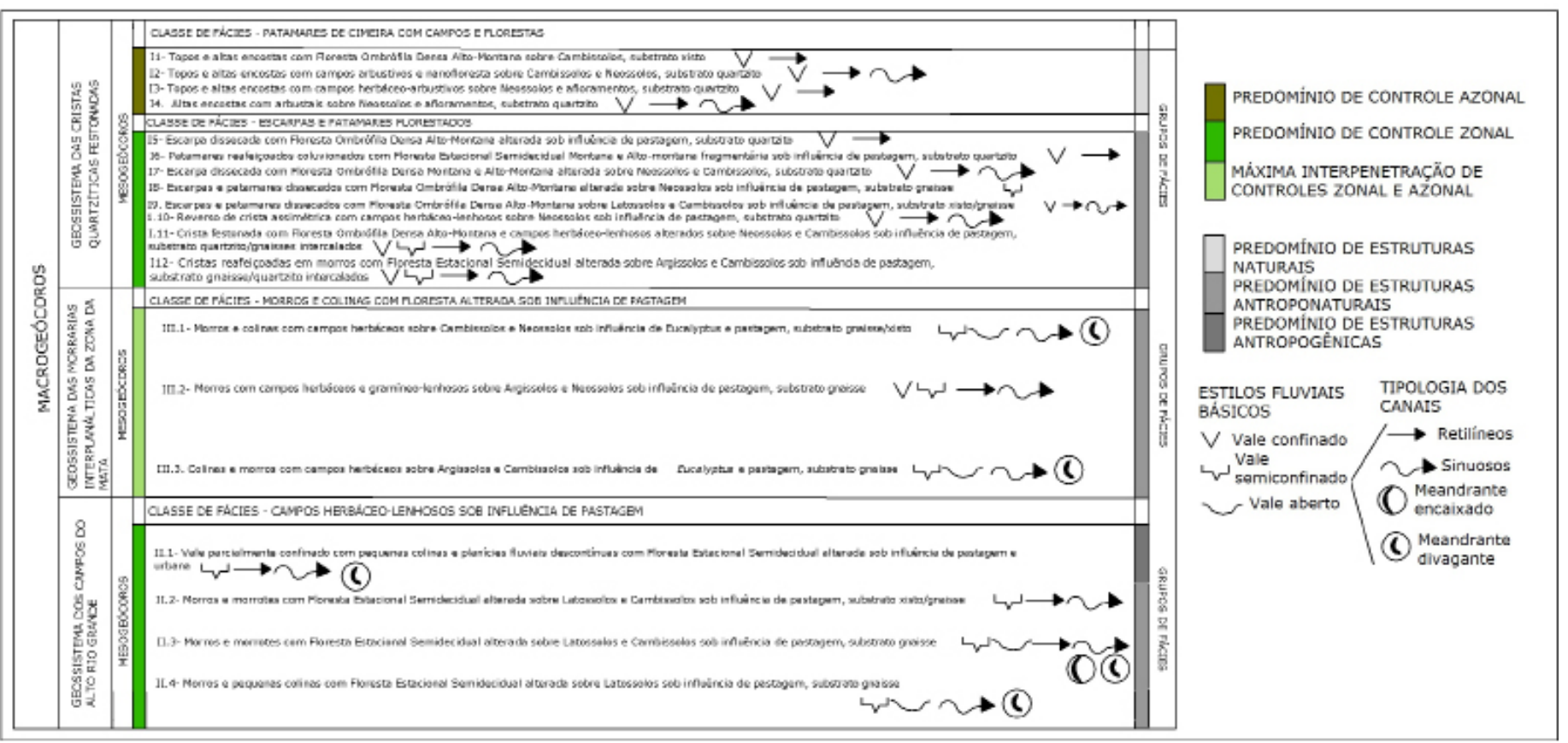

Elaborado pelo autor 
A organização se estabelece a partir de três geossistemas regionais (macrogeócoros) cujas espacialidades extravasam o perímetro do município de Lima Duarte (geossistemas das Cristas Quartzíticas Festonadas, das Morrarias Interplanálticas da Zona da Mata Mineira e dos Campos do Alto Rio Grande), consubstanciados por classes de fácies, quatro delas com ocorrência interpretada para a área de estudo, a saber: 1) Patamares de cimeira com campos e florestas; 2) Escarpas e patamares florestados; 3) Morros e colinas com floresta alterada sob a influência de pastagem; 4) Colinas e morros com campos herbáceo-lenhosos sob a influência de pastagem e Eucalyptus. Em conjunto, estas classes de fácies se dissociam em dezenove tipologias que se integram na hierarquia dos grupos de fácies, unidades adequáveis a uma grandeza topológica não elementar, ou seja, intermediária entre as áreas mais elementares (fácies) e os níveis escalares regionais que se formatam a partir dos geomas/macrogeócoros.

As classes de fácies 1 e 2 se inscrevem em um geossistema regional proposto sob a denominação de Geossistema das cristas quartzíticas festonadas, unidade que compõe destacado indivíduo geográfico na parte mais setentrional da região morfológica designada pelo Projeto RADAMBRASIL (1983) como Mantiqueira Meridional, e definem a passagem para a chamada região Setentrional em rupturas de declive bem marcadas. Tal geossistema é dado pela ordem de grandeza macrogeocórica, e as tipologias paisagísticas que se arranjam na sua composição formam mosaicos complexos caracterizados pela presença dos campos e arbustais rupestres em patamares de cimeira e em vertentes a sotavento que se manifestam em variadas sinúsias, das florestas ombrófilas e estacionais nos domínios mais intermontanos, além da influência humana expressa fundamentalmente por atividades agropastoris. Distribuindo-se em patamares altimétricos compreendidos entre 1.000 e 1.500 metros, apresenta uma zonalidade vertical bem marcada na estrutura da paisagem.

O geossistema das cristas quartzíticas, nas classes de fácies aqui mapeadas, agrega, fundamentalmente, grupos de fácies diferenciados segundo os campos rupestres, em geral em posições altimontanas, e as vertentes florestadas, nos níveis altimétricos descendentes. Caracteriza-se com eminência por ser aquele de maior fragilidade potencial em todo o município de Lima Duarte, em função dos declives acentuados e das coberturas superficiais arenosas produtos da alteração dos quartzitos, que, na presença de fitofisionomias abertas de campos rupestres, se espalham com certa facilidade ao longo dos flancos íngremes das cristas escarpadas em função da ação, sobretudo, do escoamento superficial. Eclodem, dessa maneira, diversos focos de arenização, alguns deles amplificados em função de indevidas investidas na prática de extração de areia. As coberturas pedológicas correspondem a Neossolo Litólico e Regolítico, além de algumas manchas de Neossolo Quartzarênico na Serra do Ibitipoca mapeadas por Rocha (2013), e sobre esse tipo de substrato é que se verifica uma dinâmica de encosta mais aguda, caracterizada por erosão concentrada na forma de ravinas e voçorocas, conforme apontado em estudos anteriores (MARQUES NETO et al., 2014; 2015). Tais processos se intensificam na Serra Negra e de Lima Duarte por conta de um apascentamento bovino mais intensivo, onde o pisoteio exercido pelo gado tem sido lesivo a uma tecitura superficial arenosa; na Serra do Ibitipoca tais processos se atenuam em função da presença de unidade de conservação de proteção integral (Parque Estadual do Ibitipoca).

Ao longo das cristas quartzíticas se dispõem também faixas de mata, algumas vezes mais contínuas, ora excessivamente fragmentadas, com ocorrência de Floresta Estacional Semidecidual e Floresta Ombrófila Densa. Ocorrem nas vertentes a barlavento ou em níveis xistosos e gnáissicos quando estas litologias se intercalam aos quartzitos, distribuindo-se nos flancos escarpados e patamares da Serra de Lima Duarte, onde ocorrem os grupos fisionômicos estacionais semideciduais, e das serras Negra e do Ibitipoca, que aportam as fisionomias ombrófilas densas. No extremo norte do município, Cambissolos argilosos geneticamente vinculados à alteração de xistos aportam Floresta Ombrófila Densa em vertente orientada para sul, constituindo um enclave florestal em meio aos arbustais, campos rupestres e nanoflorestas que dominam as cimeiras quartzíticas.

As cristas quartzíticas são dissecadas por drenagem paralela a subparalela em canais encaixados em vales confinados a semiconfinados, assumindo tipicidade majoritariamente retilínea em função do forte controle estrutural. A rede fluvial se relaciona com a paisagem circundante em plena cumplicidade no tocante ao intenso processo de retrabalhamento que se verifica ao longo desses importantes alinhamentos interfluviais, tanto no domínio das vertentes íngremes como dos canais turbulentos que se lançam desses flancos em demanda aos níveis de base locais. Muito embora esses diferentes comportamentos hidrodinâmicos engendrem diferentes fácies no âmbito do canal fluvial, tais integridades não foram assim mapeadas em funções das restrições impostas pela escala, atendo-se apenas aos aspectos morfológicos do vale e dos canais, recorrendo-se à legenda para a organização de tais informações para evitar-se a plotagem da rede de drenagem e dos recursos 
gráficos que seriam demandados para diferenciação dos estilos na escala trabalhada, o que deixaria o mapa deveras carregado.

A interpenetração de componentes zonais e azonais é deveras intensa no âmbito das cristas quartzíticas, predominando os primeiros nas vertentes florestadas com solos que variam de incipientes a maduros, e os segundos nos patamares de cimeira com solos imaturos sob os campos rupestres. Tal raciocínio se estabelece na concepção de Isachenko (1973), pela qual a zonalidade vertical existente em relevos montanhosos engendra uma estratificação dos componentes geográficos com a elevação altimétrica análoga à distribuição das zonas geográficas latitudinais. Indubitavelmente, ao longo das cristas se materializam geossistemas formados mediante um controle mais expressivo da litologia e dos sistemas de transformação pedológica a ela associados em detrimento do controle climático tropical, cujas estruturas destoam daquelas vigentes em paisagens tropicais típicas. A gênese do geossistema regional está ligada à própria reativação tectônica vinculada à fissão da placa afro-brasileira e aos processos tectônicos e denudacionais cenozoicos que subnivelaram suas cimeiras e promoveram sistemas acíclicos de soerguimento e dissecação das escarpas e dos patamares. Sobre este arcabouço processouse a evolução das variáveis de estado em função dos diferentes processos pedogenéticos, dos aspectos meso e microclimáticos e dos padrões de evolução da vegetação ao longo do Quaternário.

Os geossistemas formados por elementos fundamentalmente zonais se estabelecem na classe de fácies designada por Morros e colinas com floresta alterada sob influência de pastagem, paisagem de "mares de morro" onde é imperiosa a mamelonização e a geração de morfologias marcadamente convexas em função de intensiva esfoliação esferoidal em litologias gnáissicas migmatizadas ou não. Correspondem aos setores mais rebaixados do município de Lima Duarte, estando os topos subnivelados entre 900 e 1.000 metros de altitude, decaindo em demanda a passagem do rio Peixe, que estabelece o nível de base local a 700 metros acima do nível do mar. É o domínio da formação de minerais de argila enquanto unidades de alteração intempérica dominante, com ampla geração de caulinita e mantos de alteração mais profundos pedogeneizados em Latossolos que se consorciam a solos mesomaduros (Cambissolos). São geossistemas estruturalmente mais simplificados em função de sua utilização massiva para pastagem, única modalidade mais expressiva de uso da terra, que se intercala a fragmentos de Floresta Estacional Semidecidual, em grande medida correspondentes a focos de regeneração natural que se instalaram em áreas nas quais usos agrícolas produtivos foram abortados.

A faixa de mamelonização mais extensiva que nivela diferentes superfícies geomórficas na Zona da Mata Mineira tem ocorrência descontínua na área de estudo, emergindo entre a Serra Negra e de Lima Duarte e a norte desta, limitando-se a oeste com a Serra do Ibitipoca. Este geossistema é seccionado pela passagem do Rio do Peixe, que disseca diferentes litologias e intercala trechos encaixados com alta energia da corrente e extensões com planícies fluviais mais desenvolvidas, perfazendo assim um canal fundamentalmente semiconfinado com segmentos retilíneos a sinuosos e meandrantes encaixados a divagantes; no extremo leste do município, o vale se abre mais expressivamente e a planície fluvial assume maior desenvolvimento, formatando-se uma tipicidade meandrante divagante em vale não confinado. Malgrado tais vales não aparecerem no mapa, foram representados por simbologia na legenda (Figura 3), tendo sido incorporados, dessa forma, na classificação dos grupos de fácies. Na totalidade de sua extensão, o rio do Peixe intercala segmentos de forte encaixamento com extensões de planícies fluviais bem desenvolvidas associadas ou não a terraços, definindo-se zonas de alta energia com retrabalhamento intenso dos materiais provenientes das encostas dos blocos em soerguimento, bem como significativas extensões de estocagem sedimentar que engendram barreiras geoquímicas confinadas entre duas rupturas de declive.

A zona de maior interpenetração de elementos zonais e azonais se consubstancia na classe de fácies designada por Colinas com campos herbáceo-lenhosos sob influência de pastagem e Eucalyptus. Corresponde à porção de um geossistema regional que propomos designar por Geossistema dos campos do alto rio Grande, delimitado pela zona de ocorrência de campos graminosos que adentram a calha do rio em questão em demanda ao norte, entre os planaltos do Sul de Minas e àqueles dos campos das vertentes, passando a definir uma área de transição entre o domínio tropical atlântico e o Cerrado. Projetam-se de Bom Jardim de Minas em direção a Lima Duarte e Santana do Garambeu em colinas e morros com encostas suavizadas até coalescerem em composição com faixas de campo cerrado na região de Andrelândia, São Vicente de Minas e Carrancas, margeando o Planalto dos Campos das Vertentes. A classe de fácies que partilha da área de estudo tem sua delimitação a partir da calha do rio Grande, e começa a se firmar quando é transposto o interflúvio que marca a divisão entre a bacia deste rio com a do rio do Peixe, que drena em demanda ao rio Preto, já na Bacia do Rio Paraíba do Sul. São, portanto, domínios intermontanos de topografia mais suavizada emoldurada em vales semiconfinados a abertos, cuja vestimenta vegetal 
é dada por campos naturais que medram em solos imaturos, mas também em sistemas de transformação típicos do contexto climático tropical, notadamente Argissolos e mesmo Latossolos. Entendemos que estes campos naturais são relíquias paleoclimáticas mantidas em uma calha fluvial relativamente elevada ( 1.000 metros de altitude) que modera as temperaturas médias anuais, o que deve ter garantido as condições climáticas para a permanência de uma vegetação herbácea em contextos pedológicos e patamares altimétricos que aportam, nos tempos hodiernos, vegetação florestal. No extremo sul desse geossistema, que em Lima Duarte a toponímia designa como "região dos campos", ocorrem manchas de campos rupestres em quartzito sobre Neossolo Litólico e Regolítico em função do afloramento destas litologias. No mais, o restante da massa vegetal corresponde a campos limpos sobre coberturas argilosas fisico-quimicamente similares aos solos sobre os quais tem lugar a vegetação florestal.

Um interessante palimpsesto é assim verificado na região dos campos, a começar pela ocorrência de fisionomias vegetais majoritariamente herbáceas em solos de organização estrutural argilúvica. A perturbação destas áreas para pastagem é de longa data, e em alguns contextos de ocupação mais antiga chega a ser secular. No entanto, é o avanço do Eucalyptus que tem sido a maior causa de impacto ambiental nos campos nativos, sendo que em Lima Duarte já comprometeu a continuidade desta tipicidade fitofisionômica singular, e, juntamente às áreas de pastagem, diferenciam os grupos de fácies. Em alguns setores onde a vegetação foi impropriamente perturbada, tem se verificado a formação de capoeiras altas que sinalizam uma sucessão ecológica de índole latifoliada, compatível com o contexto climático atual, uma forte evidência de que pressões permanentes, profundas e espacialmente abrangentes podem implicar o desaparecimento dessas fisionomias.

A natureza dos contatos entre as unidades geossistêmicas tende a ser difusa em contextos nos quais predominam as estruturas naturais e abrupta em áreas significativamente antropizadas. A conexão entre os ambientes florestais e os campos rupestres, por exemplo, se dá pela emergência de nanoflorestas e alguns arbustais que definem autênticas faixas de tensão ecológica; os contatos entre fragmentos florestais eáreas de pastagem, em contraste, tende a ser abrupto e bem marcado, impondo ruptura nos processos superficiais e nas migrações e transformações organominerais subsuperficiais. Interdigitada ou truncada, as faixas de contato sempre estabelecem conexões, efeitos de borda, faixas de interpenetração e partilhas dinâmicas nos fluxos de matéria e energia entre as unidades que estão em parelha.
Em Lima Duarte, tais conexões são estabelecidas em geossistemas que, embora guardem muitas vezes o mesmo vínculo genético, evoluíram distintamente segundo o processo histórico de transformação da paisagem, ladeando-se assim áreas com predomínio de estruturas naturais e paisagens mais transformadas em seu uso e em sua cobertura e processos superficiais, nas quais predominam as estruturas antroponaturais. É possível observar uma área nuclear de geossistemas mais preservados em suas estruturas naturais definida nos somitais da Serra do Ibitipoca a partir do Parque, de onde se projeta o alinhamento do divisor entre a Bacia do Rio Grande e a Bacia do Rio do Peixe, sendo a antropização mais rarefeita nos níveis superiores das cristas quartzíticas. A partir desse core a transformação na paisagem se intensifica nas médias e baixas encostas, definindo-se contatos com os geossistemas mamelonizados adjacentes, geralmente, mediante a coalescência de áreas já consideravelmente alteradas.

\section{Conclusões}

Esquemas sub-regionais em estudos dos geossistemas, voltados para uma determinada bacia hidrográfica, compartimento geomorfológico ou território municipal, são importantes para um estreitamento das articulações entre as escalas regionais e locais, melhorando a precisão do plano de informações, ampliando os bancos de dados geoespaciais e fornecendo informações e conhecimentos relevantes ao planejamento e à gestão territorial. Em âmbito municipal, considerada a expressão espacial de Lima Duarte, a escala de 1/50.000 se mostrou adequada na geração de informações compatíveis com o nível de generalização admitido para o planejamento territorial municipal, estabelecendo unidades de mapeamento pelas quais os grupos de fácies, ordem de grandeza intermediária nos níveis topológicos, puderam ser traçados em compatibilidade com os mosaicos formados a partir do arranjo de ecossistemas mais elementares (fácies).

0 âmbito local de mapeamento e interpretação é transcendido na medida em que as classes de fácies mapeadas expressam de forma contundente os tipos de paisagem ocorrentes na região, consubstanciando-se a partir do arranjo de mosaicos que foram as próprias unidades de mapeamento (grupos de fácies). Partilham de importantes indivíduos geográficos regionais, formados pela interpenetração destas e de outras classes de fácies ocorrentes além da área de estudo, indivíduos estes que são unidades estratégicas para o planejamento ambiental regional. As cristas quartzíticas, a região dos campos, ou ainda os domínios de relevos mamelonizados 
excessivamente desflorestados que ocorrem na Zona da Mata, cada um deles se inscreve em diferentes contextos estruturais e dinâmicos, possuindo estados funcionais distintos e suas próprias potencialidades e capacidades de suporte. No estabelecimento dessas diferenciações, a interpretação da rede de drenagem a partir de seus estilos fluviais se projetou como de grande valia para a averiguação dos padrões de dissecação vigentes e seus desdobramentos na evolução dos vales e dos sítios deposicionais correlativos, contribuindo sobremaneira para essa articulação entre o enfoque evolutivo e dinâmico na medida em que revelou tipicidades próprias nos estilos que variam fundamentalmente segundo as classes de fácies, diferenciando-se, portanto, a partir dos tipos genéticos de geossistemas sobretudo. Embora os vales, no escopo do presente trabalho, não tenham sido individualizados como grupos de fácies, o reconhecimento dos estilos vigentes foi fundamental para a diferenciação dos grupos no contexto das classes de fácies nas quais estão inseridos, uma vez que definem aspectos morfológicos distintos e se relacionam estreitamente com os fluxos de massa e energia vigentes. Esta propriedade diferenciadora foi ainda mais funcional no tocante ao Geossistema das Morrarias Interplanálticas da Zona da Mata, onde o nivelamento altimétrico é mais bem marcado e a paisagem dotada de uma estrutura mais homogênea comparativamente às áreas montanhosas.

Dos três geossistemas regionais (macrogeócoros) que perpassam a área de estudo, dois deles se adéquam à condição de paisagens de exceção na acepção de Ab'Sáber (2006), sendo eles o Geossistema das cristas quartzíticas festonadas e o Geossistema dos campos do alto rio Grande, ao passo que o Geossistema das morrarias interplanálticas da Zona da Mata congrega as paisagens dominantes, originalmente formadas por morros florestados e atualmente organizada em mosaicos dados por várias unidades de uso e cobertura. 0 caráter de exceção se formata em função de elementos bióticos expressos em formações vegetais relictas e disjuntas que refletem francamente os fatores azonais diferenciadores, com considerável número de espécies endêmicas, bem como pelo efeito de fatores abióticos (escarpas, cachoeiras, cânions, cavernas) definidores de considerável geodiversidade. $\mathrm{Na}$ área de estudo, o caráter de exceção tem eclosão, portanto, nos domínios onde os fatores azonais são assaz influentes, devendo ser foco prioritário dos programas conservacionistas no âmbito do planejamento municipal e regional. 


\section{Referências}

ABALAKOV, A. D.; SEDYKH, S. A. (2010) Regional-typological study and mapping of geosystems: analysis of the implementation. Geography and Natural Resources, v. 31, p. 317-323.

AB'SÁBER, A. N. (2003) Os domínios de natureza do Brasil: potencialidades paisagísticas. São Paulo: Ateliê Editorial, $159 p$.

AB'SÁBER, A. N. (2006) Brasil: paisagens de exceção: o litoral e o Pantanal Mato-grossense: patrimônios básicos. Cotia/SP. Ateliê Editorial, 182p.

BERTRAND, G. (1971) Paisagem e Geografia Física Global: esboço metodológico. Caderno de Ciências da Terra, n. 13.

BRIERLEY, G. J.; FRYIRS, K. A. (2005) Geomorphology and river management: applications of the River Styles framework. Blackwell Publishing, 398p.

CAVALCANTI, L. C. S. (2013) Da descrição de áreas à Teoria dos Geossistemas: uma abordagem epistemológica sobre sínteses naturalistas. 205p. Tese (Doutorado em Geografia), Universidade Federal de Pernambuco, Recife, 2013.

DEMEK, J. (1978) The landscape as a geosystem. Geoforum, v. 19, p. 29-34.

GANZEI, K. S. (2008) The geosystems of the Southern and Middle Kuril Islands. Geography and Natural Resources, v. 29 , p. 251-255.

HASSE, G. (1989) Medium scale landscape classification in the German Democratic Republic. Landscape ecology, v. 3, n. 1, p. 29-41.

IBGE. INSTITUTO BRASILEIRO DE GEOGRAFIA E ESTATÍSTICA. (1992) Manual técnico da vegetação brasileira. Série Manuais Técnicos em Geociências, n. 1, Rio de Janeiro.

INPE. TOPODATA. Banco de dados geomorfométricos do Brasil. Disponível em: <http://www.dsr.inpe.br/topodata/ indesc/php>. Acesso em: julho de 2013.

ISACHENKO, A. G. (1973) Principles of landscape science and Physical Geography Regionalization. Melbourne, $311 \mathrm{p}$.

KHOROSHEV, A. V.; ALESHCHENKO, G. M. (2008) Methods to identify geosystems with a commonalty of intercomponent relationships. Geography and Natural Resources, v. 29, p. 267-272.

KUZMENKO, E. I. (2011) Cartographic approach in studying the structure and dynamics of geosystems as exemplified by the middle Ob region. Geography and Natural Resources, v. 32, n. 2, p. 184-189.

KUZNETSOVA, T. I.; BYCHKOV, I. V.; BATUEV, A. R.; PLYUSNIN, V. M.; RUZHNIKOV, G. M.; KHMEL'NOV, A. E. (2011) Structural-typological characteristics and ecological potential of the Baikal region's geosystems. Geography and Natural Resources, v. 32, n. 4, p. 315-322.

LAVRINENKO, I. A. (2012) Landscape diversity of specially protected natural territories of nenets autonomous okrug. Geography and Natural Resources, v. 33, n. 1, p. 37-44.

LEMOS, R. C.; SANTOS, R. D. (1978) Manual de método de trabalho de campo. Sociedade Brasileira de Ciência do Solo, $37 p$.

LIMA, R. N. S.; MARÇAL, M. S. (2013) Avaliação da condição geomorfológica da Bacia do Rio Macaé - RJ a partir da metodologia de classificação de estilos fluviais. Revista Brasileira de Geomorfologia, v. 14, n. 2, p. 171-179.

LYSANOVA, G. I.; SEMENOV, Y. M.; SOROKOVOI, A. A. (2011) Geosystems of the Upper Yenisei Basin. Geography and Natural Resources, v. 32, n. 4, p. 92-99.

MAKUNINA, G. S. (2014) The landscape-geophysical basis of geoecology. Geography and Natural Resources, v. 35, n. 2, p. 109-113.

MARQUES NETO, R. (2012) Estudo evolutivo do sistema morfoclimático e morfotectônico da Bacia do Rio Verde (MG), Sudeste do Brasil. 2012, 429p. Tese (Doutorado em Geografia), Instituto de Geociências e Ciências Exatas, Universidade Estadual Paulista. Rio Claro. 
MARQUES NETO, R.; ZAIDAN, R. T.; MENON JR., W. (2015) Mapeamento geomorfológico do município de Lima Duarte (MG). Revista Brasileira de Geomorfologia, v. 16, n. 1, p. 123-136.

MARQUES NETO, R.; ZAIDAN, R. T.; MENON JR., W.; MOURA, A. B. A. P. (2014) Estrutura e dinâmica da paisagem no município de Lima Duarte (MG): uma abordagem geoecológica. Caminhos de Geografia, v. 15, n. 52, p. 134-150.

NUNES, B. A.; RIBEIRO, M. I. C.; ALMEIDA, V. J.; NATALI FILHO, T. (1994) Manual técnico de geomorfologia. Rio de Janeiro: IBGE, 113p. (Série Manuais Técnicos em Geociências, n. 5).

OLIVEIRA, T. A. (2013) A concepção geossistêmica aplicada ao estudo da dinâmica da paisagem na Bacia Hidrográfica do Rio Lourenço Velho, sul do estado de Minas Gerais. 2013, 164p. Tese (Doutorado em Geografia), Instituto de Geociências e Ciências Exatas, Universidade Estadual Paulista, Rio Claro.

PLAKHOTNIK, A. F. (1973) The subject and structure of geosystems theory. Doklady Instituta Geografii Sibiri I Dal'nego Vostoka, n. 39, p. 33-39.

PONÇANO, W. L.; CARNEIRO, C. D. R.; BISTRICHI, C. A.; ALMEIDA, F. F. M.; PRANDINI, F. L. (1981) Mapa geomorfológico do estado de São Paulo. Vol. 1. Instituto de Pesquisas Tecnológicas, Divisão de Minas e Geologia Aplicada, 94p.

PREOBRAZHENSKIY, V. S. (1983) Geosystem as an object of landscape study. Geojournal, Wiesbaden, v. 7 n. 2.

RIABCHIKOV, A. M. (1976) Estructura y Dinâmica de la Esfera Geográfica: su desarrollo natural y transformación por el hombre. Moscou: Editorial MIR, 238p.

ROCHA, G. C. (2013) O meio físico da região de Ibitipoca: características e fragilidade. In: FORZZA, R. C.; MENINI NETO, L. SALIMENA, F. R. G.; ZAPPI, D. (Org.) Flora do Parque Estadual do Ibipipoca. Juiz de Fora: Editora UFJF, p. 27-52

RODRIGUEZ, J. M. M.; SILVA, E. V.; CAVALCANTI, A. P. (2010) Geoecologia das paisagens: uma visão geossistêmica da análise ambiental. 3. ed. Fortaleza: Edições UFC, 222p.

ROSS, J. L. S. (1992) O Registro Cartográfico dos Fatos Geomórficos e a Questão da Taxonomia do Relevo. Revista do Departamento de Geografia. FFLCH-USP, n. 6. São Paulo.

(2009) Ecogeografia do Brasil: subsídios para o planejamento ambiental. São Paulo: Oficina de Textos, 208p.

SAUSHKIN. G.; SMIRNOV, A. M. (1968) Geosystems and geostructures. Geografiya, n. 5, p. 27-32.

SOCHAVA, V. B. (1971) Geography and ecology. Soviet Geography: review and translation. New York, v. 12, n. 5, p. 277293.

(1977) O Estudo dos Geossistemas. Métodos em Questão, n. 16. USP-IGEO. São Paulo.

(1978) Por uma Teoria de Classificação dos Geossistemas da Vida Terrestre. Biogeografia. São Paulo. n. 14.

(1978) Introducción a la teoria sobre los geosistemas. Novosibirsk: Nauka, filial de Sibéria. 318p. (em russo).

STYNKO, V. A.; SEMENOV, Y. M. (2008) The study of geossystem structure, development and functioning in Siberia. Dissertations Comissions of Cultural Landscape, n. 6, p. 141-150.

SUVOROV, E. G.; KITOV, A. D. (2013) Landscape structure of the southeastern part of Eastern Sayan. Geography and Natural Resources, v. 34, n. 4, p. 371-377.

UNIVERSIDADE FEDERAL DE VIÇOSA. Fundação Centro Tecnológico de Minas Gerais; UNIVERSIDADE FEDERAL DE LAVRAS. Fundação Estadual do Meio Ambiente. Mapa de solos do Estado de Minas Gerais: legenda expandida. Belo Horizonte: Fundação Estadual do Meio Ambiente, 2010. 49p.

WALTER, H. (1984) Vegetação e zonas climáticas. São Paulo: Editora Pedagógica e Universitária. $5^{\circ}$ ed.

YEFREMOV, Y. K. (1969) The landscape sphere and the geographical environment. Soviet Geography: review and translation, v. 5, n. 5, p. 248-256.

ZONNEVELD, I. S. (1989) The land unit: a fundamental concept in landscape ecology, and its application. Landscape Ecology, v. 5, p. 67-86. 